\title{
Pomegranate extract-loaded solid lipid nanoparticles: design, optimization, and in vitro cytotoxicity study
}

This article was published in the following Dove Press journal: International Journal of Nanomedicine

\author{
Noha M Badawi' \\ Mahmoud H Teaima ${ }^{2}$ \\ Khalid M El-Say ${ }^{3}$ \\ Dalia A Attia' \\ Mohamed A El-Nabarawi ${ }^{2}$ \\ Mohey M Elmazar ${ }^{4}$ \\ 'Department of Pharmaceutics, \\ Faculty of Pharmacy, The British \\ University in Egypt, Cairo, Egypt; \\ ${ }^{2}$ Department of Pharmaceutics \\ and Industrial Pharmacy, Cairo \\ University, Cairo, Egypt; ${ }^{3}$ Department \\ of Pharmaceutics, King Abdulaziz \\ University, Jeddah, Saudi Arabia; \\ ${ }^{4}$ Department of Pharmacology, Faculty \\ of Pharmacy, The British University \\ in Egypt, Cairo, Egypt
}

Background: Pomegranate extract (PE) is a natural product with potent antioxidant and anticancer activity because of its polyphenols content. The main purpose of this study was to maximize the PE chemotherapeutic efficacy by loading it in an optimized solid lipid nanoparticles (SLNs) formula.

Materials and methods: The influence of independent variables, which were lipid concentration $\left(\mathrm{X}_{1}\right)$, surfactant concentration $\left(\mathrm{X}_{2}\right)$ and cosurfactant concentration $\left(\mathrm{X}_{3}\right)$, on dependent ones, which were particle size $\left(\mathrm{Y}_{1}\right)$, polydispersity index $\left(\mathrm{Y}_{2}\right)$, zeta potential $\left(\mathrm{Y}_{3}\right)$, entrapment efficiency $\left(\mathrm{Y}_{4}\right)$ and cumulative $\%$ drug release $\left(\mathrm{Y}_{5}\right)$, were studied and optimized using the Box-Behnken design. Fifteen formulations of PE-SLNs were prepared using hot homogenization followed by ultra-sonication technique. Response surface plots, Pareto charts and mathematical equations were produced to study the impact of independent variables on the dependent quality parameters. The anti-proliferative activity of the optimized formula was then evaluated in three different cancer cell lines, namely, MCF-7, PC-3 and HepG-2, in addition to one normal cell line, HFB-4. Results: The results demonstrated that the particle sizes ranged from 407.5 to $651.9 \mathrm{~nm}$ and the entrapment efficiencies ranged from 56.02 to $65.23 \%$. Interestingly, the $50 \%$ inhibitory concentration of the optimized formula had more than a 40 -fold improved effect on the cell growth inhibition in comparison with its free counterpart. Furthermore, it was more selective against cancer cells than normal cells particularly in MCF-7 breast cancer cells.

Conclusion: These data proved that nanoencapsulation of PE enhanced its anticancer efficacy. Therefore, our results suggested that a PE-loaded SLNs optimized-formula could be a promising chemotherapeutic agent.

Keywords: pomegranate extract, solid lipid nanoparticles, Box-Behnken design, optimization, cancer cell lines

\section{Introduction}

Cancer is a serious disease where the control of growth in one or more cells is lost, causing either a solid mass of cells recognized as a tumor or a liquid cancer (ie, bone marrow or blood-related cancer). It is one of the largest causes of death worldwide and the major treatments include chemotherapy, surgery, and radiotherapy. ${ }^{1}$ Chemotherapy comprises of treatment with low-molecular-weight drugs in order to destroy tumor cells selectively or, as a minimum, restrict their proliferation. Gastrointestinal tract lesions, bone marrow suppression, nausea, hair loss, and the development of clinical resistance are the main drawbacks of several cytotoxic agents. These side effects exist because cytotoxic agents act on both cancer and normal cells. ${ }^{2}$
Correspondence: Noha M Badawi Department of Pharmaceutics, Faculty of Pharmacy, The British University in Egypt, El Sherouk City, Suez Desert Road, Cairo, Egypt Tel +20201005350058 $\mathrm{Fax}+2022630$ 0010/20

Email noha.alaa@bue.edu.eg 
Since ancient periods, natural products and natural bioactive compounds have been utilized by human beings to treat numerous diseases. Remarkably, natural products have been used in recent times for the treatment and prevention of cancer. ${ }^{3,4}$

The fruit of the Punica granatum L. tree (pomegranate) has been recognized since prehistoric times for its aids to health. ${ }^{5}$ Pomegranate extract (PE) and its individual polyphenols reveal in vitro and in vivo anticancer effects. ${ }^{6} \mathrm{PE}$, containing mainly ellagitannins, shows anti-invasive, antiproliferative, proapoptotic, and anti-inflammatory effects in different cancer cell lines in vitro ${ }^{7}$ such as breast cancer, ${ }^{8}$ prostate cancer, ${ }^{9}$ lung tumors, colon cancer, ${ }^{10}$ and skin cancer in mice xenograft models and culture plates. ${ }^{11}$

It was found that various PE formulations decreased the proliferation of both types of breast cancer cells which are estrogen-receptor positive and estrogen-receptor negative, ${ }^{8}$ in addition to MMTV-Wnt-1 mouse mammary cancer stem cells, ${ }^{12}$ mammary organ culture, ${ }^{13}$ and moreover decreased the motility and invasion of SUM 149 and MDA-231 cell lines resulting from aggressive cancers. ${ }^{14}$ These detected findings were accompanied by inhibition of NF- $\kappa$ B expression ${ }^{14}$ and also inhibition of aromatase enzyme (17b-hydroxysteroid dehydrogenase), that catalyzes conversion of estrone to estradiol. ${ }^{15}$ Estradiol was found to increase the risk of breast cancer in postmenopausal women. ${ }^{16}$ It was also previously demonstrated that PE can induce apoptosis and inhibit cell growth in mice implanted with prostate cancer (PC-3 cell line) by modulating the proteins that regulate apoptosis. ${ }^{17,18}$ In addition, PE has been found to induce chemoprevention of liver cancer through antiproliferative, antioxidant and proapoptotic mechanisms. ${ }^{19}$

However, although many natural products have been confirmed to have a strong therapeutic efficacy, their low bioavailability and poor solubility have seriously restricted their usage. ${ }^{11}$ Nanotechnology is considered as one of the most advanced disciplines that has proved successful yields and mechanisms in defeating cancer; ${ }^{20}$ its approaches are employed to cancer therapeutic agents in order to reduce toxicity, improve stability and bioavailability and endorse selective tumor uptake. ${ }^{21}$ Therefore, encapsulation of PE into biodegradable and biocompatible nanoparticles may overcome this problem.

Solid lipid nanoparticles (SLNs) are a good choice for the delivery of both hydrophilic and hydrophobic anticancer drugs. The main reason why SLNs show high drug-loading capacity, improve the blood circulation time, control release kinetics, and increase the overall therapeutic effectiveness of anti-cancer drugs is their lipid core. ${ }^{22,23}$ In addition, SLNs have been considered as novel nanoparticulate carrier systems due to enhanced delivery and stability of drugs. ${ }^{24}$

Optimization is a method that uses the available resources to achieve the best probable results so that it is implemented for the design and development of a wide range of controlledrelease dosage forms. The optimization technique has now replaced the process of trial-and-error which was widely used and thus it is found in a wide diversity of applications in the chemistry and pharmaceutical industry. Employment of applicable experimental designs, production of polynomial relationships and optimum research techniques via appropriate software are represented by such studies. ${ }^{25}$

We hypothesized that encapsulation of PE in SLNs would improve their anticancer activity. Therefore, the main objective of this study was to develop, characterize and optimize SLNs loaded with PE. The Box-Behnken design (BBD), using Statgraphics ${ }^{\circledR}$ plus software (Manugistics Inc., Rockville, MD, USA), was applied to detect the critical parameters that influence the characteristics of the prepared PE-SLNs in order to select the optimum formula. Subsequently, the anti-proliferative effect of the optimized formula was evaluated in vitro in MCF-7, PC-3 and HepG-2 cancer cell lines as well as one normal cell line, HFB-4, and then compared to the free PE as well as the void optimized formula.

\section{Materials and methods Materials}

PE was purchased from Shaanxi Ciyuan Biotech Co., Ltd (Shaanxi, China). Stearic acid, disodium hydrogen phosphate and potassium dihydrogen phosphate were purchased from El-Nasr Pharmaceutical Chemicals Co. (Cairo, Egypt). Tween 80 and lecithin were generously donated by Egyptian International Pharmaceutical Industries Co. (10th of Ramadan City, Egypt). Dialysis tubing cellulose membrane with molecular weight cutoff 12,000 Dalton was purchased from Sigma-Aldrich Co (St Louis, MO, USA). Dimethyl sulfoxide (DMSO), MTT assay and trypan blue dye were purchased from Sigma-Aldrich Co. Fetal bovine serum, DMEM, RPMI-1640, HEPES buffer solution, L-glutamine, gentamycin and $0.25 \%$ Trypsin-EDTA were purchased from Lonza (Bornem, Belgium). All other chemicals were of analytical grade.

\section{Design of experiments}

The BBD three-level three-factor $\left(3^{3}\right)$ was implemented in the present study by the use of statistical package Statgraphics ${ }^{\circledR}$ plus software, version 4. It was applied to optimize the 
Table I Independent and dependent variables and their levels for Box-Behnken design

\begin{tabular}{llll}
\hline Independent variables & \multicolumn{2}{l}{ Levels } & \\
\cline { 2 - 4 } & $-\mathbf{I}$ & $\mathbf{0}$ & $+\mathbf{I}$ \\
\hline Lipid concentration, \%, $\left(\mathrm{X}_{1}\right)$ & 4 & 6 & 8 \\
Surfactant concentration, \%, $\left(\mathrm{X}_{2}\right)$ & 3 & 4 & 5 \\
Cosurfactant concentration, $\mathrm{mg},\left(\mathrm{X}_{3}\right)$ & 100 & 125 & $\mathbf{I} 50$ \\
\hline Dependent variables & & Constraints \\
\hline Particle size $\left(\mathrm{Y}_{1}\right)$ & & Minimize \\
Polydispersity index $\left(\mathrm{Y}_{2}\right)$ & & Minimize \\
Zeta potential $\left(\mathrm{Y}_{3}\right)$ & & Maximize \\
Entrapment efficiency $\left(\mathrm{Y}_{4}\right)$ & & Maximize \\
Cumulative \% release $\left(\mathrm{Y}_{5}\right)$ & & Maximize \\
\hline
\end{tabular}

formulation variables statistically in order to prepare PESLNs, with the aim of achieving optimum particle size, polydispersity index (PDI), zeta potential, high encapsulation efficiency percent and sustained cumulative drug release. Fifteen runs were designed; 12 of them acted as the midpoint to each edge of the multidimensional cube while the remaining three were the duplicates of the cube's center point. Three different independent variables were estimated: lipid (stearic acid) concentration $\left(\mathrm{X}_{1}\right)$, surfactant (tween 80) concentration $\left(\mathrm{X}_{2}\right)$ and cosurfactant (lecithin) concentration $\left(\mathrm{X}_{3}\right)$, while the particle size $\left(\mathrm{Y}_{1}\right)$, PDI $\left(\mathrm{Y}_{2}\right)$, zeta potential $\left(\mathrm{Y}_{3}\right)$, entrapment efficiency $(\mathrm{EE})\left(\mathrm{Y}_{4}\right)$ and cumulative \% drug release $\left(\mathrm{Y}_{5}\right)$ were chosen as dependent variables. The independent and dependent variables are presented in Table 1. The composition of the prepared PE-SLNs according to BBD is shown in Table 2. Desirability was estimated for selection

Table 2 Composition of the $3^{3}$ Box-Behnken design for formulations of pomegranate extract-loaded solid lipid nanoparticles

\begin{tabular}{llll}
\hline $\begin{array}{l}\text { Formulae } \\
\text { code }\end{array}$ & $\begin{array}{l}\text { Lipid } \\
\text { concentration } \\
(\%)\end{array}$ & $\begin{array}{l}\text { Surfactant } \\
\text { concentration } \\
(\%)\end{array}$ & $\begin{array}{l}\text { Cosurfactant } \\
\text { concentration } \\
\text { (mg) }\end{array}$ \\
\hline FI & 6 & 4.0 & 125.0 \\
F2 & 4 & 4.0 & 100.0 \\
F3 & 8 & 4.0 & 150.0 \\
F4 & 6 & 5.0 & 150.0 \\
F5 & 4 & 4.0 & 150.0 \\
F6 & 8 & 5.0 & 125.0 \\
F7 & 8 & 4.0 & 100.0 \\
F8 & 6 & 4.0 & 125.0 \\
F9 & 6 & 3.0 & 100.0 \\
FI0 & 4 & 3.0 & 125.0 \\
FII & 8 & 3.0 & 125.0 \\
FI2 & 6 & 3.0 & 150.0 \\
FI3 & 6 & 5.0 & 100.0 \\
FI4 & 4 & 5.0 & 125.0 \\
FI5 & 6 & 4.0 & 125.0 \\
\hline
\end{tabular}

of the optimized formula which was exposed for additional investigations. ${ }^{25}$

\section{Preparation of PE-SLNs}

Hot homogenization followed by the ultra-sonication technique was selected for the preparation of PE-SLNs. ${ }^{26}$ The lipid phase was prepared by melting stearic acid, lecithin as well as $\mathrm{PE}$ at $10^{\circ} \mathrm{C}$ above the lipid melting point. Meanwhile, the dissolving of tween 80 in deionized water and then heating to the same temperature of the lipid phase was carried out for the preparation of the aqueous phase. The hot aqueous phase was then added gradually into the lipid phase with continuous stirring using a magnetic stirrer in a water bath for $30 \mathrm{~min}$. Subsequently, sonication of the coarse oil in water $(\mathrm{o} / \mathrm{w})$ emulsion was done using a probe sonicator (Vibra-Cell ${ }^{\mathrm{TM}}$ VCX130; Sonics, CT, USA) in an ice bath at $100 \%$ amplitude for $10 \mathrm{~min}$. The obtained dispersions were collected in glass containers and stored in the refrigerator for further experiments.

\section{Characterization of the prepared PE-SLNs}

The 15 prepared formulae were examined for particle size, PDI, zeta potential, EE\% in addition to cumulative \% drug release.

\section{Measurements of particle size, PDI and zeta potential}

The dynamic light scattering (DLS) technique was chosen for particle size as z-average diameter, PDI, and zeta potential of PE-SLNs evaluation by the using of Zetasizer Nano-Zs90, MPT-Z (Malvern Instruments Ltd, Malvern, UK). Dilution with deionized water was carried out for the prepared PE-SLNs before evaluation to achieve optimal kilo counts per second (kcps) of 50 to 200 for measurements. ${ }^{27}$

\section{Morphological analysis}

The morphology of the prepared PE-SLNs dispersion was evaluated by using $5 \mu \mathrm{L}$ of the dispersion which was placed onto the surface of a 300-mesh copper grid coated with carbon and then examined by using transmission electron microscopy (TEM) (JEM-2100, JEOL, Tokyo, Japan), operated at an acceleration voltage of $200 \mathrm{kV}$. The samples were firstly negatively stained using $2 \%$ uranyl acetate $(\mathrm{w} / \mathrm{v})$, followed by air drying for $15 \mathrm{~min}$ and then the excess was removed by filter paper. ${ }^{28}$

\section{EE\% determination}

EE\% was examined by measuring the amount of free drug in the aqueous phase after separation of the system using the 
centrifugation method. PE-SLNs dispersion was centrifuged at $12,000 \mathrm{rpm}$ and $4^{\circ} \mathrm{C}$ for $1 \mathrm{~h}$ using cooling centrifuge (2-16KL, Sigma Laborzentrifugen GmbH, Osterode am Harz, Germany); then the supernatant was collected and diluted with phosphate buffer saline $\mathrm{pH} 7.4$ (PBS 7.4) to measure the free drug concentration. ${ }^{29}$ The drug concentration was measured at $265 \mathrm{~nm}$ using ultraviolet-visible spectrophotometer (V-630, Jasco, Tokyo, Japan). ${ }^{30}$ The percentage of entrapped drug was calculated according to the following equation: ${ }^{27}$

$$
\mathrm{EE}(\%)=\frac{W_{\text {initial drug }}-W_{\text {free drug }}}{W_{\text {initial drug }}} \times 100
$$

where $W_{\text {initial drug }}$ was the amount of drug used for the assay and $W_{\text {free drug }}$ was the amount of free drug detected in the aqueous phase after centrifugation.

\section{In vitro drug release study}

The dialysis bag method was selected for accomplishing the in vitro drug release study by using PBS 7.4 as the dissolution medium $^{27}$ and dialysis membrane with a molecular weight of 12,000 Da which retains SLNs and permits the diffusion of free drug into the dissolution medium. The bags were initially soaked in PBS 7.4 for $24 \mathrm{~h}$ before being used; then $2 \mathrm{~mL}$ of PE-SLNs dispersion was transferred into the bag and the two ends tied by string. ${ }^{27}$ Subsequently, the bags were placed in $100 \mathrm{~mL}$ dissolution medium which was maintained at $37^{\circ} \mathrm{C}$ and shaken at $100 \mathrm{rpm}$ in a thermostatically controlled shaking water bath (WSB-18, Daihan Scientific Co. Ltd, Gangwon-do, Korea). The first eight samples were withdrawn every hour and then one sample was withdrawn after $24 \mathrm{~h}$ and the final sample after $48 \mathrm{~h}$. Samples were withdrawn at predetermined time intervals, replenished with fresh buffer to retain the sink condition and analyzed spectrophotometrically at $265 \mathrm{~nm}^{30}$

\section{Prediction of the optimized formula}

The optimized formula was predicted after analysis of data using the Statgraphics ${ }^{\circledR}$ plus software by applying constraints on all independent variables to acquire the optimum particle size, PDI, zeta potential, high EE\% and sustained cumulative drug release. In addition, drug-loading capacity was calculated for the optimized formula using the following equation: ${ }^{31}$

$$
\mathrm{LC}(\%)=\frac{W_{\text {initial drug }}-W_{\text {unbound drug }}}{W_{\text {lipid }}} \times 100
$$

To check the validity of the calculated optimal formulation influences and the expected responses established by the software, the recommended optimized formula was prepared and evaluated.

\section{In vitro cytotoxicity study of the PE-SLNs optimized formula \\ Cytotoxicity evaluation using viability MTT assay}

In this experiment, a cytotoxicity study against three different cancer cell lines as well as a normal cell line was evaluated for the optimized SLNs formula loaded with PE and without $\mathrm{PE}$ (void) in addition to the free PE. The concentrations that induced $50 \%$ growth inhibition as a result of exposure to the optimized PE-SLNs formula, the void optimized formula and the free PE were obtained and compared.

Cell lines chosen for the study and their propagation Three different cancer cell lines, namely, human breast carcinoma (MCF-7), human prostate carcinoma (PC-3), and human hepatocellular carcinoma (HepG2) in addition to human normal melanocytes (HFB-4) were bought from the American Type Culture Collection (Rockville, MD, USA). Cells were grown in RPMI-1640 supplemented with 10\% inactivated fetal calf serum and $50 \mu \mathrm{g} / \mathrm{mL}$ gentamycin. The cells were kept at $37^{\circ} \mathrm{C}$ in a humidified, $5 \% \mathrm{CO}_{2}$ atmosphere and sub-cultured 2 to 3 times a week.

\section{Antiproliferative activity (MTT assay)}

The growing cells from different tumor cell lines were incubated in Corning ${ }^{\circledR} 96$-well tissue culture plates $\left(5 \times 10^{4}\right.$ cell/ well) for $24 \mathrm{~h}$ in order to attach the cells to the wall of the plate. Afterward, samples were added into the well plates to accomplish 10 concentrations $(1-500 \mu \mathrm{g} / \mathrm{mL})$ of each sample and then incubated for $24 \mathrm{~h}$ using vehicle $(0.5 \%$ DMSO) as a control. Concisely, the viability of the treated cells was examined by MTT assay in this way, the media was removed and substituted with $100 \mu \mathrm{L}$ of fresh culture RPMI-1640 medium then $10 \mu \mathrm{L}$ of the $12 \mathrm{mM}$ MTT stock solution (5 mg of MTT in $1 \mathrm{~mL}$ of PBS). Subsequently, cells were kept at $37^{\circ} \mathrm{C}$ and $5 \% \mathrm{CO}_{2}$ for $4 \mathrm{~h}$ and then $85 \mu \mathrm{L}$ aliquot of the media was discarded from the wells and $50 \mu \mathrm{L}$ of DMSO was added and mixed carefully. The cells were then incubated at $37^{\circ} \mathrm{C}$ for $10 \mathrm{~min}$. To determine the number of viable cells, the optical density was measured at $590 \mathrm{~nm}$ with the SunRise ${ }^{\mathrm{TM}}$ microplate reader (Tecan Inc., NC, USA) and the percentage of viability was calculated. In addition, the relation between surviving cells and drug concentration was plotted to develop the survival curve of each tumor 
cell line after treatment with the specified compound. The concentration that caused $50 \%$ inhibition of cell growth in addition to a 95\% CI was obtained using GraphPad Prism 5 software (San Diego, CA, USA). ${ }^{32,33}$

\section{Results}

The mean particle size $\left(\mathrm{Y}_{1}\right)$ ranged from 407.5 to $651.9 \mathrm{~nm}$ depending on the variables level selected during production as displayed in Table 3. PDI $\left(\mathrm{Y}_{2}\right)$ values ranged from 0.329 to 0.601 where all formulations showed good homogeneity. Furthermore, all formulations exhibited negative zeta potential $\left(\mathrm{Y}_{3}\right)$ which were in the range of -29.8 to $-45.5 \mathrm{mV}$ and the $\mathrm{EE} \%\left(\mathrm{Y}_{4}\right)$ was in the range of $56.02 \%$ to $65.23 \%$ due to the variation in factors combination. Moreover, cumulative $\%$ drug release $\left(\mathrm{Y}_{5}\right)$ after $48 \mathrm{~h}$ ranged from $60.36 \%$ to $75.53 \%$ as shown in Table 3.

\section{Estimation of the quantitative effects of the factors}

The analysis of variance for investigating the model according to the data of the responses $\left(\mathrm{Y}_{1}\right.$ to $\left.\mathrm{Y}_{5}\right)$ is presented in Table 4. The influence of factor is considered significant if the effects differ from zero and the $p$-value $<0.05$ as stated by ANOVA. A synergistic effect is identified by a positive sign, while an antagonistic effect of the factor is represented by a negative sign. Results in Table 4 show the estimated effects of the selected factors, and the associated $p$-values for the five responses resulting from ANOVA.
Based on the obtained results from Table $4, X_{1}$ had a significant antagonistic effect on $\mathrm{Y}_{2}$ and $\mathrm{Y}_{4}$ with $p$-values of 0.0015 and 0.0001 , respectively, but it had a significant synergistic effect on $\mathrm{Y}_{5}$ with a $p$-value of 0.0003 . In addition, $\mathrm{Y}_{1}$ was significantly affected by the antagonistic effect of $\mathrm{X}_{2}$ and $\mathrm{X}_{3}$ with $p$-values of 0.0054 and 0.0018 , respectively. $\mathrm{X}_{3}$ had a significant synergistic effect on $\mathrm{Y}_{3}$ with a $p$-value of 0.0001 , but it had a significant antagonistic effect on $\mathrm{Y}_{5}$ with a $p$-value of 0.0219 . Furthermore, $\mathrm{Y}_{3}$ was significantly affected by the synergistic effect of the quadratic term of $\mathrm{X}_{3}^{2}$ with a $p$-value of 0.0029 ; however, $\mathrm{X}_{2}$ and the interaction effect of $\mathrm{X}_{1}$ and $\mathrm{X}_{3}$ affected $\mathrm{Y}_{3}$ antagonistically with $p$-values of 0.035 and 0.0408 , respectively. On the other hand, $\mathrm{Y}_{4}$ was significantly affected by the synergistic effect of the quadratic term of $\mathrm{X}_{1}{ }^{2}$ and $\mathrm{X}_{2}{ }^{2}$ with $p$-values of 0.0030 and 0.0347 , respectively, and the antagonistic effect of the quadratic term of $\mathrm{X}_{3}^{2}$ with a $p$-value of 0.0390 .

\section{In vitro cytotoxicity study of the optimized formula}

Results of the cytotoxicity study showed that PE had a statistically anti-proliferative effect on the MCF-7 breast cancer cell line with a $50 \%$ inhibitory concentration $\left(\mathrm{IC}_{50}\right)$ of $49.2 \mu \mathrm{g} / \mathrm{mL}$ with $95 \%$, CI (29.75 to 78.06) followed by the PC-3 prostate cancer cell line with $\mathrm{IC}_{50}$ of $107 \mu \mathrm{g} / \mathrm{mL}$ with $95 \%, \mathrm{CI}(80.98$ to 133.1); the lowest effect was on the HepG-2 liver cell line with $\mathrm{IC}_{50}$ of $219 \mu \mathrm{g} / \mathrm{mL}$ with $95 \%$, CI (186.4 to 310.0 ), while the cytotoxicity on normal cells (HFB-4) showed higher $\mathrm{IC}_{50}$ of $280 \mu \mathrm{g} / \mathrm{mL}$ with $95 \%$, CI (189.4 to 452.1$)$.

Table 3 Observed values of responses for 15 formulations of pomegranate extract solid lipid nanoparticles

\begin{tabular}{|c|c|c|c|c|c|}
\hline \multirow{2}{*}{$\begin{array}{l}\text { Formulation } \\
\text { code }\end{array}$} & \multicolumn{5}{|c|}{ Observed responses $\left(Y_{1}\right.$ to $\left.Y_{5}\right)$} \\
\hline & $\begin{array}{l}\text { Particle } \\
\text { size* (nm) }\end{array}$ & PDI* & $\begin{array}{l}\text { Zeta potential* } \\
(\mathrm{mV})\end{array}$ & $\begin{array}{l}\text { Entrapment } \\
\text { efficiency* (\%) }\end{array}$ & $\begin{array}{l}\text { Cumulative } \\
\text { release* (\%) }\end{array}$ \\
\hline $\mathrm{FI}$ & $427.9 \pm 9.2$ & $0.49 \pm 0.081$ & $-34.4 \pm 2.8$ & $60.26 \pm 1.9$ & $68.14 \pm 3.0$ \\
\hline F2 & $623.3 \pm 11.3$ & $0.50 \pm 0.067$ & $-29.8 \pm 2.1$ & $56.02 \pm 2.6$ & $75.53 \pm 3.9$ \\
\hline F3 & $548.9 \pm 15.3$ & $0.48 \pm 0.021$ & $-40.4 \pm 3.8$ & $65.23 \pm 3.2$ & $60.36 \pm 2.9$ \\
\hline F4 & $499.3 \pm 7.5$ & $0.52 \pm 0.045$ & $-30.4 \pm 2.7$ & $61.89 \pm 4.1$ & $62.35 \pm 3.8$ \\
\hline F5 & $407.5 \pm 6.3$ & $0.60 \pm 0.025$ & $-45.5 \pm 1.5$ & $58.96 \pm 2.2$ & $70.48 \pm 2.7$ \\
\hline F6 & $610.3 \pm 8.4$ & $0.54 \pm 0.07 \mid$ & $-32.5 \pm 3.1$ & $63.85 \pm 3.4$ & $64.10 \pm 3.5$ \\
\hline F7 & $625.3 \pm 14.4$ & $0.58 \pm 0.036$ & $-32.5 \pm 4.1$ & $62.56 \pm 3.9$ & $66.35 \pm 2.8$ \\
\hline F8 & $456.6 \pm 15.6$ & $0.56 \pm 0.018$ & $-33.0 \pm 1.6$ & $61.38 \pm 2.4$ & $66.7 I \pm 3.1$ \\
\hline F9 & $651.9 \pm 6.9$ & $0.37 \pm 0.059$ & $-32.1 \pm 3.3$ & $58.26 \pm 3.8$ & $73.28 \pm 2.6$ \\
\hline FIO & $567.5 \pm 10.9$ & $0.46 \pm 0.081$ & $-33.1 \pm 2.2$ & $59.92 \pm 2.7$ & $66.47 \pm 3.4$ \\
\hline FII & $579.1 \pm 17.1$ & $0.42 \pm 0.014$ & $-36.7 \pm 4.3$ & $62.19 \pm 1.8$ & $62.22 \pm 1.9$ \\
\hline $\mathrm{FI} 2$ & $599.1 \pm 8.7$ & $0.34 \pm 0.026$ & $-36.4 \pm 3.4$ & $61.24 \pm 2.5$ & $66.56 \pm 3.6$ \\
\hline $\mathrm{FI} 3$ & $504.6 \pm 12.5$ & $0.4 I \pm 0.037$ & $-31.5 \pm 2.6$ & $60.15 \pm 3.6$ & $64.88 \pm 2.4$ \\
\hline $\mathrm{FI} 4$ & $525.9 \pm 14.6$ & $0.32 \pm 0.098$ & $-30.4 \pm 3.2$ & $61.54 \pm 4.2$ & $67.20 \pm 3.2$ \\
\hline FI5 & $473.7 \pm 16.9$ & $0.38 \pm 0.076$ & $-33.0 \pm 2.8$ & $59.33 \pm 1.6$ & $66.63 \pm 4.1$ \\
\hline
\end{tabular}

Note: *Results are expressed as the mean of three replicates \pm SD. Abbreviation: PDI, polydispersity index. 
Table 4 Statistical ANOVA of the responses $\left(Y_{1}\right.$ to $\left.Y_{5}\right)$ results

\begin{tabular}{|c|c|c|c|c|c|c|c|c|c|c|}
\hline \multirow[t]{2}{*}{ Factors } & \multicolumn{2}{|c|}{$\begin{array}{l}\text { Particle size } \\
\left(Y_{1}\right), \mu \mathrm{m}\end{array}$} & \multicolumn{2}{|l|}{ PDI $\left(Y_{2}\right)$} & \multicolumn{2}{|c|}{$\begin{array}{l}\text { Zeta potential } \\
\left(\mathbf{Y}_{3}\right), \mathrm{mV}\end{array}$} & \multicolumn{2}{|c|}{$\begin{array}{l}\text { Entrapment } \\
\text { efficiency }\left(\mathbf{Y}_{4}\right), \%\end{array}$} & \multicolumn{2}{|c|}{$\begin{array}{l}\text { Cumulative release } \\
\left(\mathrm{Y}_{5}\right), \%\end{array}$} \\
\hline & Estimate & $p$-value & Estimate & $p$-value & Estimate & $p$-value & Estimate & $p$-value & Estimate & $p$-value \\
\hline$X_{1}$ & -15.15 & 0.6833 & $0.4 \mid 4667$ & $0.0015^{*}$ & 0.825 & 0.4496 & 60.3233 & $0.000 I^{*}$ & 67.16 & $0.0003 *$ \\
\hline$X_{2}$ & -164.375 & $0.0054^{*}$ & 0.263 & 0.1376 & -2.9 & $0.0345 *$ & 9.23 & 0.9289 & -13.1275 & 0.1599 \\
\hline$x_{3}$ & -212.575 & $0.0018^{*}$ & 0.07375 & 0.5358 & 11.725 & $0.000 I^{*}$ & 0.08 & 0.1810 & -2.495 & $0.0219 *$ \\
\hline$X_{1} X_{1}$ & 40.4917 & 0.4677 & -0.02775 & 0.2918 & -0.86667 & 0.5838 & 1.325 & $0.0030 *$ & -4.9625 & 0.3983 \\
\hline$X_{1} X_{2}$ & 36.4 & 0.4954 & -0.0724 I & 0.2438 & -0.75 & 0.6207 & 6.74167 & 0.0730 & 2.055 & 0.6866 \\
\hline$x_{1} x_{3}$ & 19.7 & 0.7072 & 0.078 & 0.8470 & -3.9 & $0.0408 *$ & -2.73 & 0.0794 & -0.915 & 0.6290 \\
\hline$x_{2} X_{2}$ & $15.44 \mid 7$ & 0.7766 & -0.012 & 0.7020 & 0.283333 & 0.8558 & -2.65 & $0.0347^{*}$ & I.I & 0.3785 \\
\hline$x_{2} x_{3}$ & 23.75 & 0.6518 & $-0.0249 \mid$ & 0.2742 & -1.75 & 0.2735 & 3.61167 & 0.6291 & 2.15 & 0.7418 \\
\hline$X_{3} X_{3}$ & 26.5417 & 0.6286 & 0.0725 & 0.7456 & 8.03333 & $0.0029 *$ & -0.62 & $0.0390 *$ & 0.745 & 0.5083 \\
\hline $\mathrm{R}^{2} \%$ & \multicolumn{2}{|c|}{92.41} & \multicolumn{2}{|c|}{90.60} & \multicolumn{2}{|c|}{97.36} & \multicolumn{2}{|c|}{97.24} & \multicolumn{2}{|c|}{94.83} \\
\hline Adj-R ${ }^{2}$ & \multicolumn{2}{|c|}{78.74} & \multicolumn{2}{|c|}{73.69} & \multicolumn{2}{|c|}{92.61} & \multicolumn{2}{|c|}{92.27} & \multicolumn{2}{|c|}{85.53} \\
\hline SEE & \multicolumn{2}{|c|}{49.53} & \multicolumn{2}{|c|}{0.06} & \multicolumn{2}{|c|}{$\mathrm{I} .42$} & \multicolumn{2}{|c|}{1.21} & \multicolumn{2}{|c|}{2.14} \\
\hline MAE & \multicolumn{2}{|c|}{24.26} & \multicolumn{2}{|c|}{0.029} & \multicolumn{2}{|c|}{0.73} & \multicolumn{2}{|c|}{0.59} & \multicolumn{2}{|c|}{1.04} \\
\hline
\end{tabular}

Note: *Significant effect of factors on individual responses.

Abbreviations: ANOVA, analysis of variance; PDI, polydispersity index; $\mathrm{X}_{1}$, lipid concentration; $\mathrm{X}_{2}$, surfactant concentration; $\mathrm{X}_{3}$, cosurfactant concentration; $\mathrm{R}^{2}$, $\mathrm{R}$-squared; Adj-R ${ }^{2}$, adjusted R-squared; SEE, standard error of estimate; $M A E$, mean absolute error.

In addition, the optimized formula scored $\mathrm{IC}_{50}$ values of $1.05 \mu \mathrm{g} / \mathrm{mL}$ with $95 \%$, CI (0.6090 to 1.419$), 2.63 \mu \mathrm{g} / \mathrm{mL}$ with $95 \%$, CI (1.898 to 6.991), $5.68 \mu \mathrm{g} / \mathrm{mL}$ with $95 \%$, CI $(2.932$ to 10.97 ) and $19.34 \mu \mathrm{g} / \mathrm{mL}$ with $95 \%$, CI (16.01 to 23.37 ) in MCF-7, PC-3 and HepG-2 cancer cell lines as well as the HFB-4 normal cell line, respectively. Furthermore, the void optimized formula recorded $\mathrm{IC}_{50}$ values of $4.516 \mu \mathrm{g} / \mathrm{mL}$ with 95\%, CI (3.193 to 6.389), $6.43 \mu \mathrm{g} / \mathrm{mL}$ with 95\%, CI (4.472 to 9.245$)$, and $11.5 \mu \mathrm{g} / \mathrm{mL}$ with $95 \%$, CI (8.355 to 15.87$)$ in MCF-7, PC-3 and HepG-2 cancer cell lines, respectively.

\section{Discussion}

\section{Response surface methodology for optimization of PE-SLNs}

In this study, BBD was employed to optimize and evaluate the main, interaction and quadratic effects of the independent variables at different levels on the dependent variables. Considerable variations between the responses were obtained based on the different combinations of variables and variable levels.

The results revealed that the size distribution exhibited good unimodal behavior as shown in Figure 1 for batch F1 as a sample. Additionally, Figure 2 shows the TEM images of the PE-SLNs; obtained from batch F5 as an example as all the images obtained were similar, which showed spherical particles with no evident sign of aggregation. In addition, all formulations showed negative zeta potential since lipid nanoparticles have negative charge on their surface due to the presence of terminal carboxylic groups in the lipids. ${ }^{34}$ Furthermore, Figure 3 displays the in vitro release profiles of PE-SLNs dispersion, which revealed a biphasic release pattern characterized by a rapid initial burst drug release

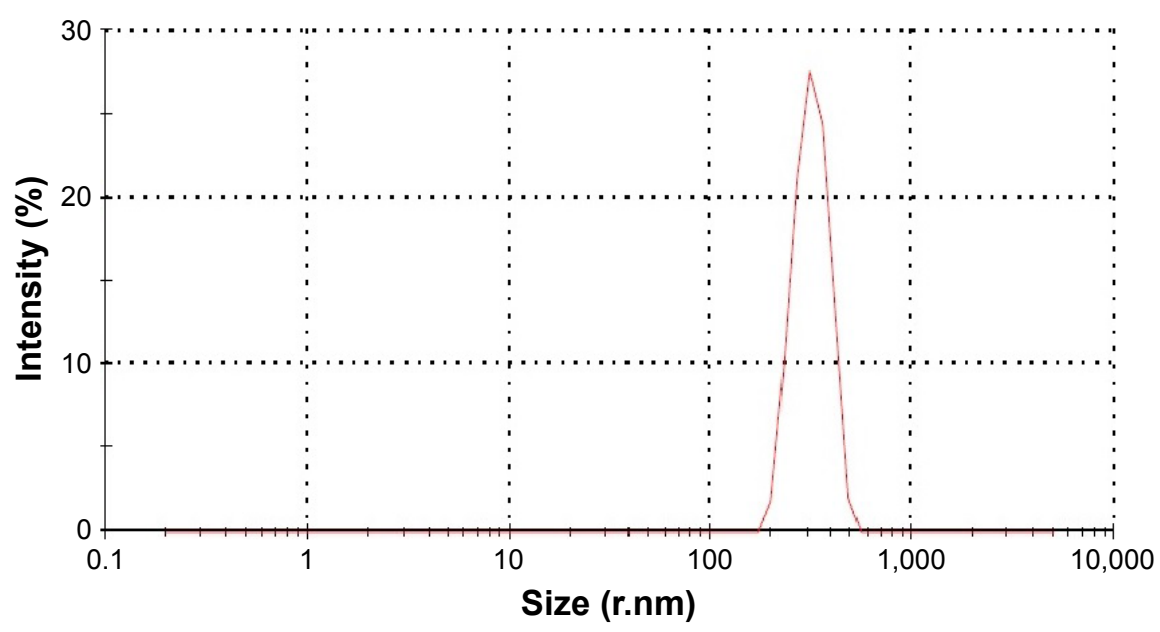

Figure I Particle size distribution for batch FI. 

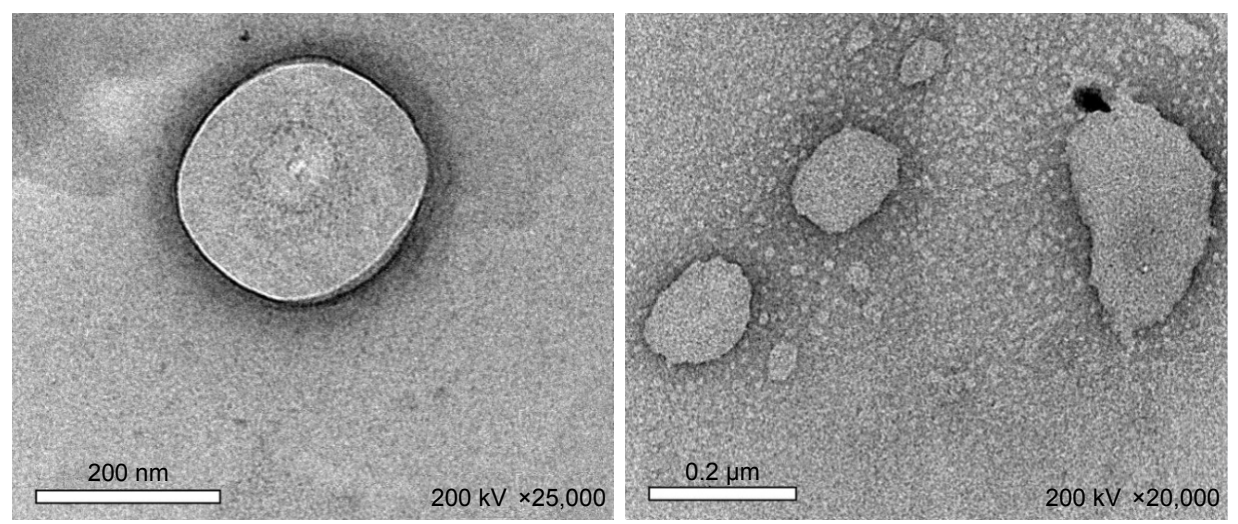

Figure 2 Transmission electron microscopy image for pomegranate extract solid lipid nanoparticles obtained from batch F5.

followed by sustained release and this behavior has been stated for SLNs. ${ }^{35,36}$

To illustrate the influence (in decreasing order of importance) of the independent variables and their interactions on the dependent ones, Pareto charts were constructed (Figure 4). The chart involves a vertical reference line at the critical $p$-value of 0.05 where the effect that exceeds the vertical line is considered to be statistically significant. In addition, 3D response surfaces (Figure 5) were created according to the model polynomial functions to estimate the change of the response surface.

From the obtained results, it is obvious that $\mathrm{X}_{1}$ and $\mathrm{Y}_{2}$ have a direct relationship which could also be attributed to the fact that lipid concentration was increased, viscosity of the dispersed phase was also increased which gave rise to particle aggregation that led to higher particle size and PDI and reduced homogenization efficiency ${ }^{37}$ In addition, $X_{1}$ had the main effect on $\mathrm{Y}_{4}$ where a direct correlation was detected
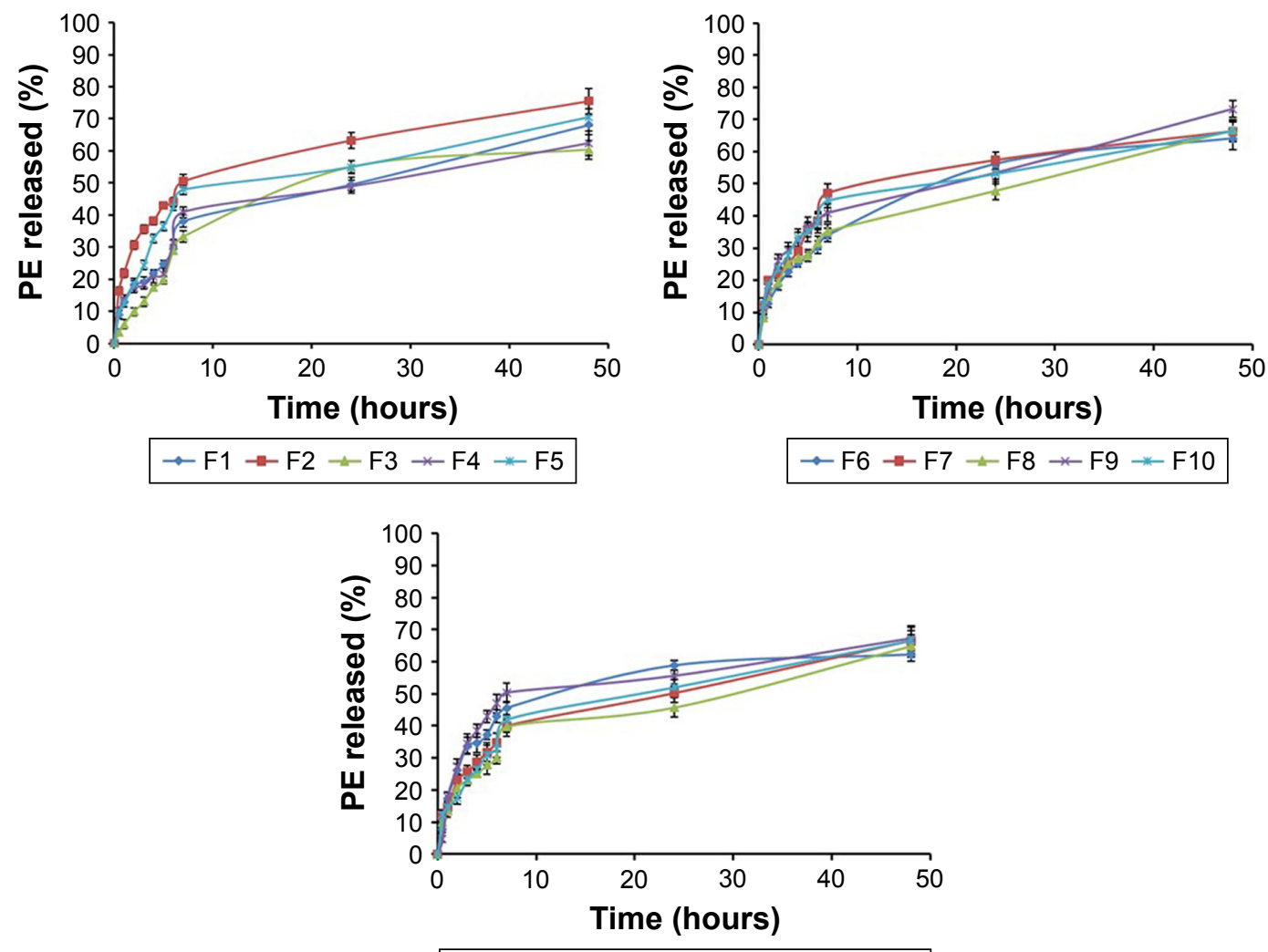

$$
\rightarrow \mathrm{F} 11 \rightarrow \mathrm{F} 12 \rightarrow \mathrm{F} 13 \rightarrow \mathrm{F} 14 \rightarrow \mathrm{F} 15
$$

Figure 3 In vitro release of stearic acid SLNs-loaded PE through cellulose membrane after $48 \mathrm{~h}$. Abbreviations: $\mathrm{PE}$, pomegranate extract; SLNs, solid lipid nanoparticles. 

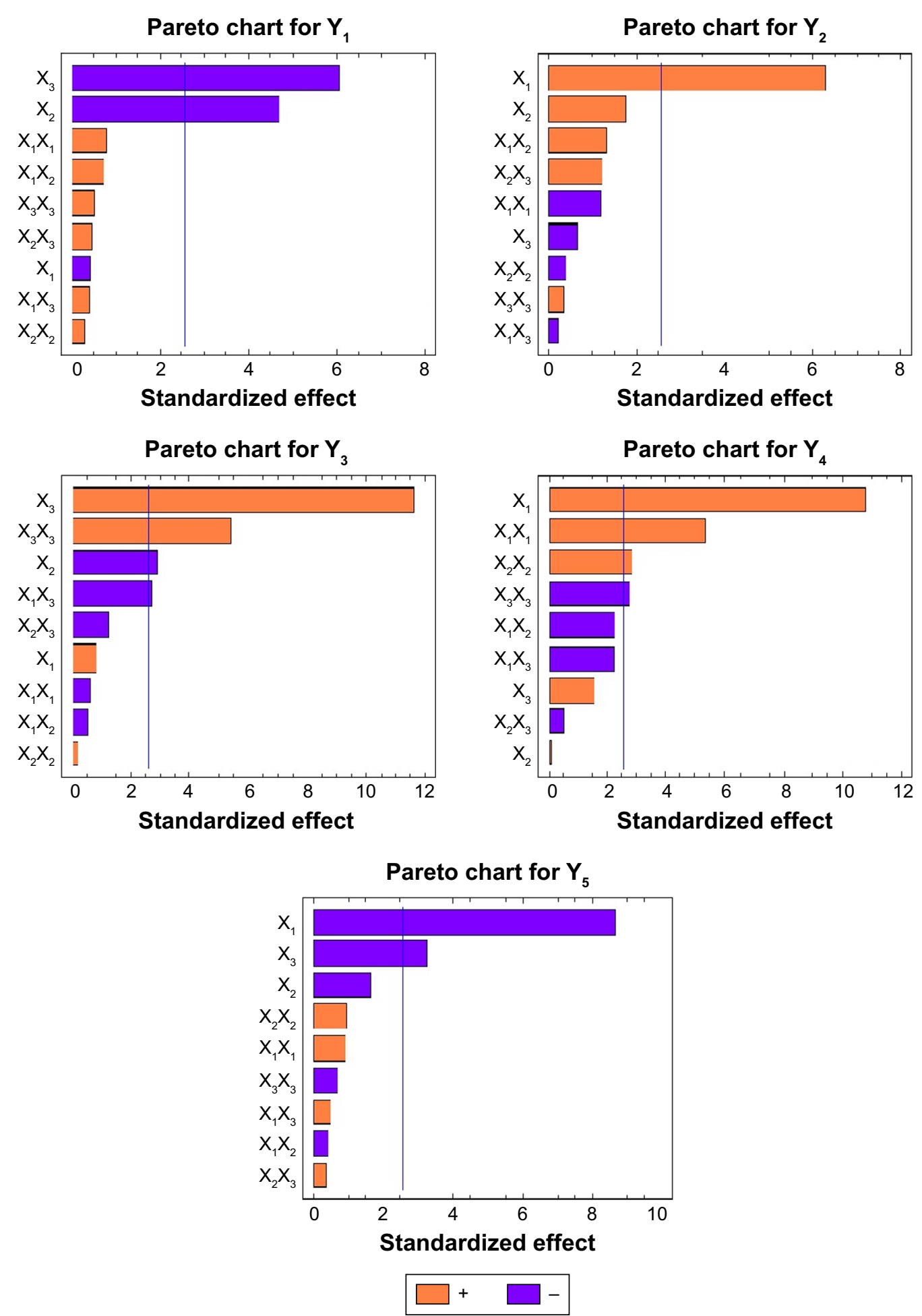

Figure 4 Pareto charts of all independent variables on $Y_{1}, Y_{2}, Y_{3}, Y_{4}$, and $Y_{5}$.

Abbreviations: $X_{1}$, lipid concentration; $X_{2}$, surfactant concentration; $X_{3}$, cosurfactant concentration; $Y_{1}$, particle size; $Y_{2}$, polydispersity index; $Y_{3}$, zeta potential; $Y_{4}$, entrapment efficiency; $Y_{5}$, cumulative \% drug release.

and this could be as a result of the higher amount of lipid which offered extra space to accommodate an excess amount of drug during the preparation of SLNs which led to a reduction in the diffusion rate of the drug into the external phase as viscosity of the lipid phase was higher and thus showed higher EE. ${ }^{37,38}$ On the other hand, $\mathrm{X}_{1}$ had a negative effect on $Y_{5}$ which could be explained by increasing the particle size and subsequently decreasing the specific surface area and, 
A
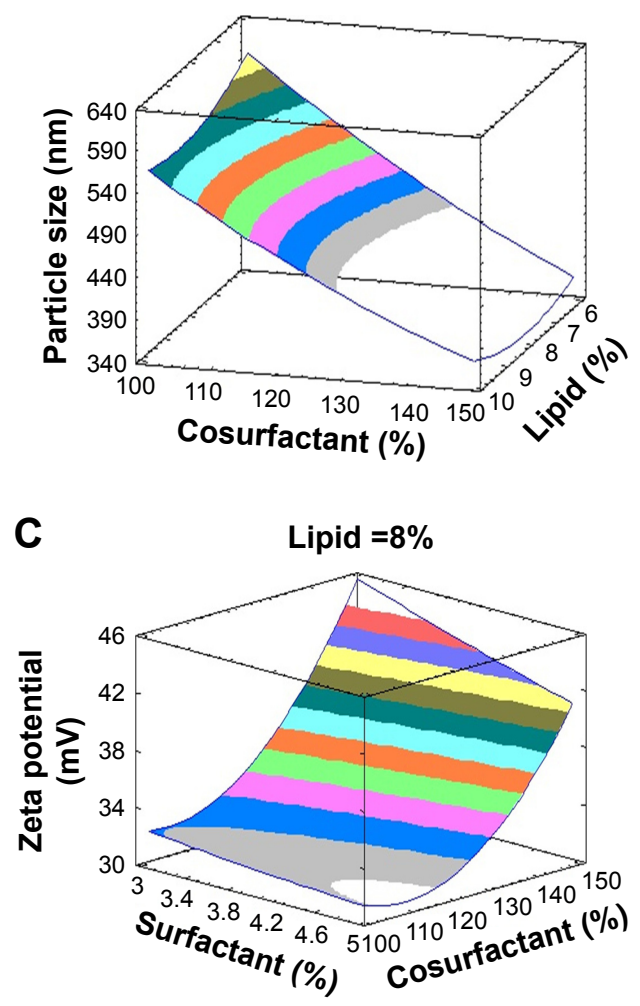

B

Lipid $=8 \%$

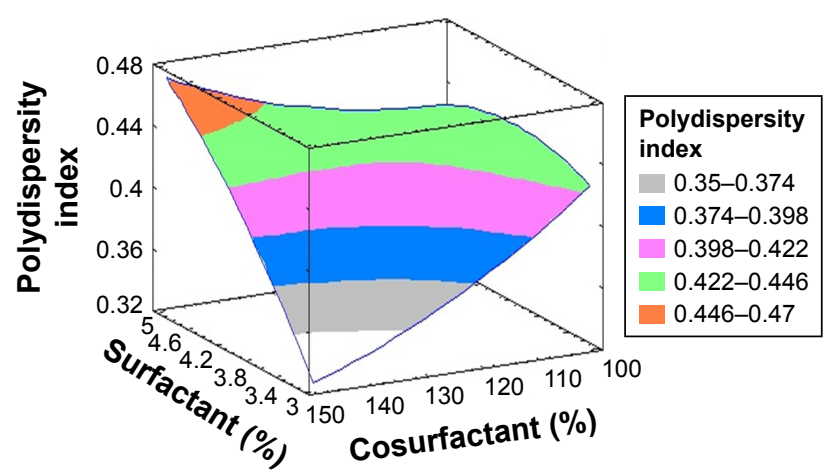

D
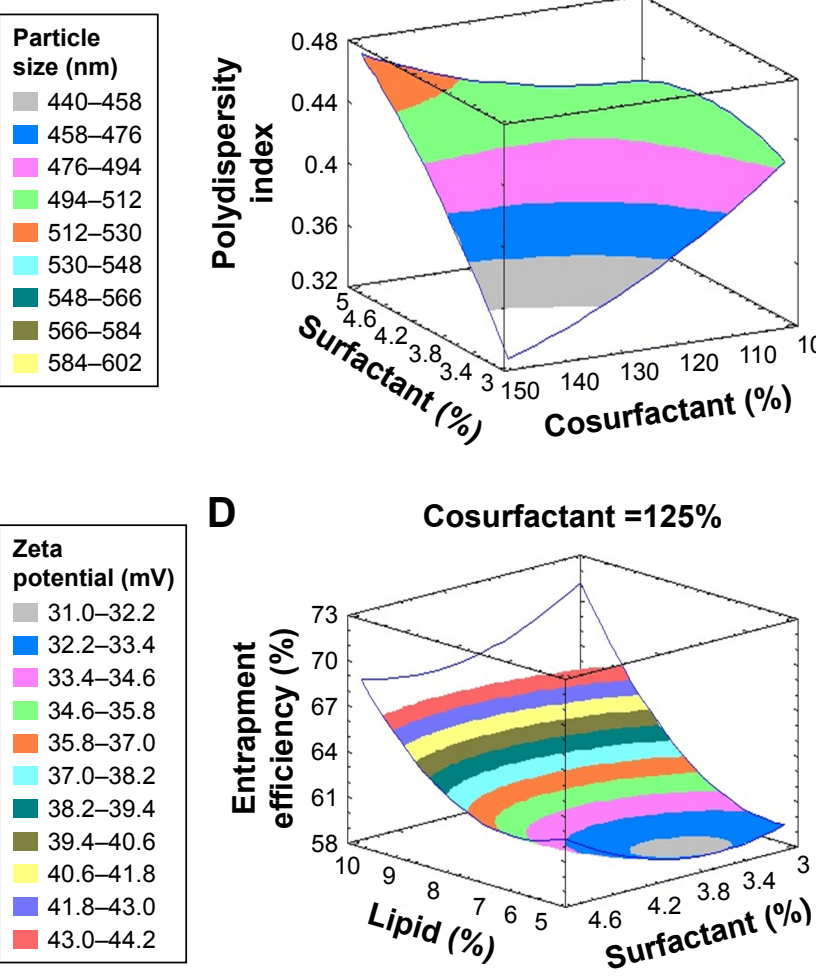

\begin{tabular}{|c|}
\hline $\begin{array}{c}\text { Entrapment } \\
\text { efficiency (\%) }\end{array}$ \\
$58.0-58.8$ \\
$58.8-59.6$ \\
$59.6-60.4$ \\
$60.4-61.2$ \\
$61.2-62.0$ \\
$62.0-62.8$ \\
$62.8-63.6$ \\
$63.6-64.4$ \\
$64.4-65.2$ \\
$65.2-66.0$ \\
$66.0-66.8$ \\
\hline
\end{tabular}

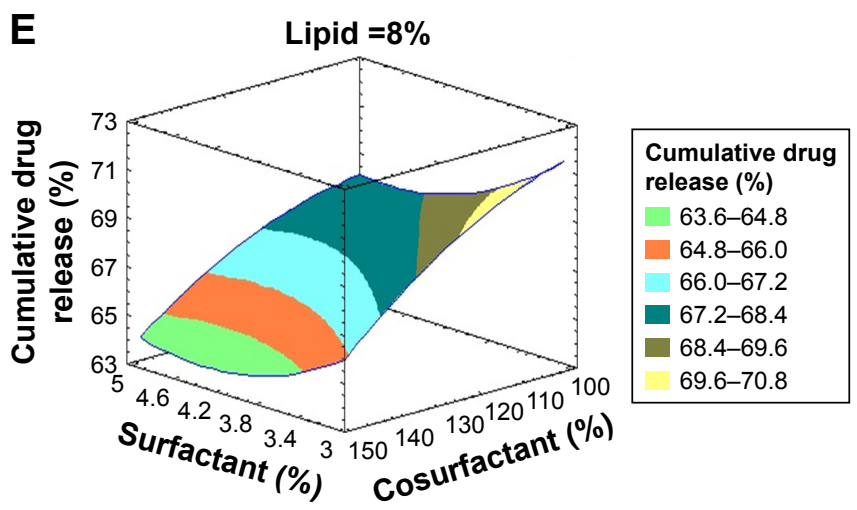

Figure 5 Estimated three-dimensional response surfaces plot for the effect of the studied variables on (A) particle size, (B) polydispersity index, (C) zeta potential, (D) entrapment efficiency \% and (E) cumulative \% drug release.

therefore, reducing the release rate.$^{39}$ Furthermore, high lipid concentration leads to high medium viscosity and more rigid solidified nanoparticles which would also slow down the drug diffusion to the dissolution medium. ${ }^{40}$

It was observed that $X_{2}$ and $X_{3}$ had a direct relationship with $Y_{1}$ that could be explained by the reduction in the interfacial tension between lipid and aqueous phase when increasing the concentration of tween 80 and lecithin which may control the aggregation of lipid particles by facilitating the particle partition thus resulting in lower size. ${ }^{41}$ Additionally, as stated before, higher surfactant concentration stabilizes the lipid matrix successfully by developing a steric barrier on their surface, thus avoiding aggregation. ${ }^{42}$

On the other hand, $\mathrm{X}_{2}$ had a negative impact on $\mathrm{Y}_{3}$ which may be due to the surface coverage of the SLNs which reduces the electrophoretic mobility of the particles and thus lowers the zeta potential. ${ }^{43}$ However, $\mathrm{X}_{3}$ showed a positive effect on $\mathrm{Y}_{3}$ which may be due to the ionic nature of lecithin that broadens the electric double layer surrounding the nanoparticles and increases the zeta potential. ${ }^{44}$ A negative influence on $Y_{5}$ was observed due to $X_{3}$, which could be due to the stabilization role of the cosurfactant, since the higher 
cosurfactant content stabilizes the SLN, and it also restricts the amount of drug released outside SLN. ${ }^{45}$

\section{Mathematical modeling and statistical analysis of the experimental data}

Analysis of the values for the responses $\left(\mathrm{Y}_{1}\right.$ to $\left.\mathrm{Y}_{5}\right)$ of the formulations of PE-SLNs was performed using Statgraphics ${ }^{\circledR}$ plus software and Equations 3 to 7 show the mathematical model for each response:

$$
\begin{aligned}
& \text { Particle size }\left(Y_{1}\right) \\
& =2,838.16-145.796 X_{1}-276.129 X_{2}-13.0358 X_{3} \\
& \\
& +5.06146 X_{1}^{2}+9.1 X_{1} X_{2}+0.197 X_{1} X_{3} \\
& \\
& +7.72083 X_{2}^{2}+0.475 X_{2} X_{3}+0.0212333 X_{3}^{2}
\end{aligned}
$$

$$
\begin{aligned}
& \operatorname{PDI}\left(\mathrm{Y}_{2}\right) \\
&= 0.524417+0.147583 \mathrm{X}_{1}-0.200708 \mathrm{X}_{2} \\
&-0.00961167 \mathrm{X}_{3}-0.00905208 \mathrm{X}_{1}^{2}+0.0195 \mathrm{X}_{1} \mathrm{X}_{2}(4) \\
&- 0.00012 \mathrm{X}_{1} \mathrm{X}_{3}-0.0124583 \mathrm{X}_{2}^{2}+0.00145 \mathrm{X}_{2} \mathrm{X}_{3} \\
&+ 0.0000168667 \mathrm{X}_{3}^{2} \\
& \text { Zeta potential }\left(\mathrm{Y}_{3}\right) \\
&=41.5542+7.56458 \mathrm{X}_{1}-3.291670 \mathrm{X}_{2} \\
& \quad+0.920167 \mathrm{X}_{3}-0.108333 \mathrm{X}_{1}^{2}-0.01875 \mathrm{X}_{1} \mathrm{X}_{2} \\
& \quad-0.039 \mathrm{X}_{1} \mathrm{X}_{3}+0.141667 \mathrm{X}_{2}^{2}-0.035 \mathrm{X}_{2} \mathrm{X}_{3} \\
&+ 0.00642667 \mathrm{X}_{3}^{2}
\end{aligned}
$$

Entrapment efficiency \% $\left(\mathrm{Y}_{4}\right)$

$$
\begin{aligned}
= & 23.0733+5.13333 \mathrm{X}_{1}-7.39667 \mathrm{X}_{2}+0.985767 \mathrm{X}_{3} \\
& +0.842708 \mathrm{X}_{1}^{2}-0.6825 \mathrm{X}_{1} \mathrm{X}_{2}-0.0265 \mathrm{X}_{1} \mathrm{X}_{3} \\
& +1.80583 \mathrm{X}_{2}^{2}-0.0124 \mathrm{X}_{2} \mathrm{X}_{3}-0.00279067 \mathrm{X}_{3}^{2}
\end{aligned}
$$

Cumulative $\%$ release $\left(\mathrm{Y}_{5}\right)$

$$
\begin{aligned}
= & 135.769-7.85188 X_{1}-9.88 X_{2}+0.07015 X_{3} \\
& +0.256875 X_{1}^{2}-0.22875 X_{1} X_{2}+0.011 X_{1} X_{3} \\
& +1.075 X_{2}^{2}+0.0149 X_{2} X_{3}-0.001268 X_{3}^{2}
\end{aligned}
$$

\section{Prediction of the optimized PE-SLNs formulation}

Analysis of the experimental factors was performed to assess the examined responses so as to reach factors levels with optimum combination which maximize the desirability function. The optimum formulation of the PE-loaded SLN system was designated based on the criteria of achieving the maximum value of $\mathrm{EE}$, cumulative $\%$ drug release, zeta potential and minimizing the particle size, PDI by applying the numerical point prediction optimization method of the Statgraphics ${ }^{\circledR}$ plus software. The responses at optimal combination of independent variables were done to confirm the validity of the calculated optimal factors and the expected responses. The composition of the optimized formula, the observed and predicted responses and the residual values for the responses are illustrated in Table 5. Based on these results, it can be concluded that the optimized combination of the independent variables confirmed the preferred particle size, PDI, zeta potential, EE\% and cumulative \% drug release. In addition, the drug-loading capacity was found to be $1.86 \%$, indicating high drug-loading capacity and the result obtained is in agreement with that obtained by Tran et al. ${ }^{46}$

\section{In vitro cytotoxicity study of the optimized formula}

Figure 6 shows the results of the MTT cell proliferation assay which was done to examine the cytotoxicity effect of the optimized PE-SLNs formula on the viability of different cancer cell lines compared to the free PE and the void optimized formula by determination of their $\mathrm{IC}_{50}(95 \%, \mathrm{CI})$.

The highest effect of $\mathrm{PE}$ on the MCF-7 cancer cell line is consistent with the great efficacy of $\mathrm{PE}$ against breast cancer cells found earlier, ${ }^{6,7,12,47}$ while the lower effect of PE was noticed on both PC-3 and HepG-2 cancer cell lines. ${ }^{48-50}$ On the other hand, it was observed that the $\mathrm{IC}_{50}$ value on the HFB-4 normal cell line was higher by 5.7-fold and 2.6-fold compared to MCF-7 and PC-3 cancer cell lines, respectively, which might indicate the selective toxicity of PE against these cancer cells.

Table 5 Composition of the optimized formula of PE-loaded SLNs with the predicted, observed and residual values of the responses

\begin{tabular}{llllll}
\hline Variables & Optimum & Responses & Predicted & Observed & Residuals* \\
\hline Lipid concentration (\%) & 4 & Particle size & 288.7 & 280 & 8.7 \\
& & Polydispersity index & 0.27 & 0.32 & -0.05 \\
Surfactant concentration (\%) & 5 & Zeta potential & 42.3 & 41.9 & 0.4 \\
& & Entrapment efficiency & 62.3 & 62.56 & -0.3 \\
Cosurfactant concentration (mg) & \multirow{2}{*}{149.433} & Cumulative \% release & 71.7 & 72.5 & -0.8 \\
\hline
\end{tabular}

Note: $*$ Residual $=$ predicted - observed.

Abbreviations: PE, pomegranate extract; SLNs, solid lipid nanoparticles. 

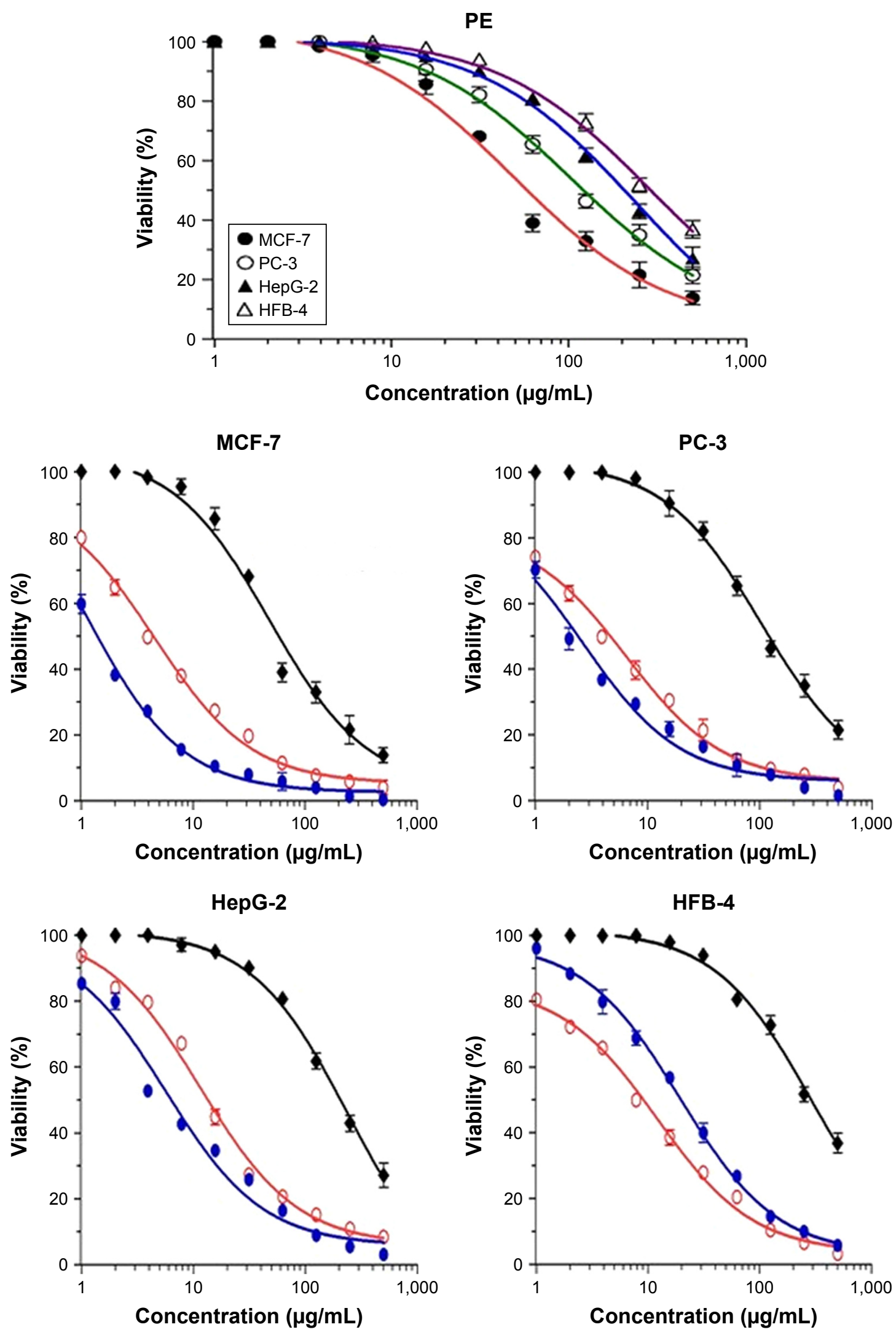

\section{$\checkmark$ PE O Void optimized formula $\quad$ PE-SLNs optimized formula}

Figure 6 Cytotoxicity profile of the free PE, PE-SLNs-optimized formula and the void optimized formula against HepG-2, PC-3, MCF-7 and HFB-4 cell lines. Abbreviations: PE, pomegranate extract; PE-SLNs, pomegranate extract-solid lipid nanoparticles; void, PE-free. 
However, the effect of PE on HepG-2 was not statistically significant when compared with its effect on HFB-4.

To decide whether nanoencapsulation improved the biological activity of PE or not, we compared the influence of free PE against their nanoprototypes (PE-SLNs optimized formula) on the same cancer cell lines. The effect of the optimized formula on MCF-7 was significant statistically when compared with other cell lines. Accordingly, this data is of the utmost importance since as noticeable, the PE-SLNs-optimized formula was superiorly more cytotoxic and effective, reducing the $\mathrm{IC}_{50}$ values by 47 -fold for breast cancer followed by 40 -fold for prostate cancer, and 38 -fold for liver cancer in comparison to the free PE. This may be due to the fact that PE-SLNs provide a safe delivery system which enhances the efficacy of pomegranate bioactive compounds and thus enhances the bioactivity of the chemopreventive phytochemicals from pomegranates. ${ }^{6}$ Remarkably, the higher $\mathrm{IC}_{50}$ value of the optimized formula on the HFB-4 normal cell line was observed by 18.4-, 7.4- and 3.4-fold over the MCF-7, PC-3 and HepG-2 cancer cell lines, respectively. This indicates that the optimized formulation has a higher selectivity profile and works preferentially against cancer cells.

Furthermore, the void optimized formula was examined for its cytotoxic effect to determine the influence of the ingredients used on the cancer cells. The only significant finding was the difference in $\mathrm{IC}_{50}$ between the PE-SLNs-optimized formula and the void-optimized formula on the MCF-7 cell line. These results could be attributed to the effect of stearic acid, the main component of our SLNs, which has been previously reported for its anticancer effect by inducing apoptosis on breast cancer, ${ }^{51}$ prostate cancer particularly on the $\mathrm{PC}-3$ cell line ${ }^{52}$ and liver cancer. ${ }^{53}$

\section{Conclusion}

Formulations of PE-SLNs were optimized and the optimized formula was developed using BBD which was successfully implemented to statistically optimize the formulation variables. It was found that the lipid concentration had the main effect on the PDI, EE and cumulative drug release. In addition, the surfactant concentration had a significant effect on the particle size and zeta potential. Furthermore, the cosurfactant concentration had the main effect on the particle size, zeta potential and cumulative drug release. The performed cytotoxicity study on different cancer cells that was carried out for optimized PE-SLNs formula, free $P E$ and void optimized formula verified that encapsulation of PE in SLNs enhances their bioefficacy, particularly on $\mathrm{MCF}-7$ breast cancer cells where the $\mathrm{IC}_{50}$ was reduced from
49.2 to $1.05 \mu \mathrm{g} / \mathrm{mL}$ by 47 -fold. Moreover, the optimized formula showed a preferential cytotoxicity against cancer cells compared to normal cells. Furthermore, we propose the optimized PE-SLNs formula as the formula of choice for further investigations of $\mathrm{PE}$ as a promising anticancer agent, particularly for breast cancer.

\section{Author contributions}

MHT, DAA, MAE and MME conceived and designed the study. KME performed the Box-Benhken design and prepared all figures and tables for optimization. NMB performed all laboratory experiments. MHT, DAA, MAE and MME supervised the work. NMB wrote the manuscript and DAA and MME edited the final version. All authors contributed toward data analysis, drafting and critically revising the paper and agree to be accountable for all aspects of the work.

\section{Disclosure}

The author reports no conflicts of interest in this work.

\section{References}

1. Shewach DS, Kuchta RD. Introduction to cancer chemotherapeutics. Chem Rev. 2009;109(7):2859-2861.

2. Thurston DE. Chemistry and Pharmacology of Anticancer Drugs. Boca Raton, FL: CRC Press; 2006.

3. Jagtap S, Meganathan K, Wagh V, Winkler J, Hescheler J, Sachinidis A. Chemoprotective mechanism of the natural compounds, epigallocatechin3-O-gallate, quercetin and curcumin against cancer and cardiovascular diseases. Curr Med Chem. 2009;16(12):1451-1462.

4. Lee KW, Bode AM, Dong Z. Molecular targets of phytochemicals for cancer prevention. Nat Rev Cancer. 2011;11(3):211-218.

5. Jurenka JS. Therapeutic applications of pomegranate (Punica granatum L.): a review. Altern Med Rev. 2008;13(2):128-144.

6. Shirode AB, Bharali DJ, Nallanthighal S, Coon JK, Mousa SA, Reliene R. Nanoencapsulation of pomegranate bioactive compounds for breast cancer chemoprevention. Int J Nanomed. 2015;10:475-484.

7. Shirode AB, Kovvuru P, Chittur SV, Henning SM, Heber D, Reliene R. Antiproliferative effects of pomegranate extract in MCF-7 breast cancer cells are associated with reduced DNA repair gene expression and induction of double strand breaks. Mol Carcinogen. 2014;53(6): 458-470.

8. Kim ND, Mehta R, Yu W, et al. Chemopreventive and adjuvant therapeutic potential of pomegranate (Punica granatum) for human breast cancer. Breast Cancer Res Treat. 2002;71(3):203-217.

9. Sartippour MR, Seeram NP, Rao JY, et al. Ellagitannin-rich pomegranate extract inhibits angiogenesis in prostate cancer in vitro and in vivo. Int J Oncol. 2008;32(2):475-480.

10. Khan N, Hadi N, Afaq F, Syed DN, Kweon MH, Mukhtar H. Pomegranate fruit extract inhibits prosurvival pathways in human A549 lung carcinoma cells and tumor growth in athymic nude mice. Carcinogenesis. 2007;28(1):163-173.

11. Bharali DJ, Siddiqui IA, Adhami VM, et al. Nanoparticle delivery of natural products in the prevention and treatment of cancers: current status and future prospects. Cancers (Basel). 2011;3(4):4024-4045.

12. Dai Z, Nair V, Khan M, Ciolino HP. Pomegranate extract inhibits the proliferation and viability of MMTV-Wnt-1 mouse mammary cancer stem cells in vitro. Oncol Rep. 2010;24(4):1087-1091. 
13. Mehta R, Lansky E. Breast cancer chemopreventive properties of pomegranate (Punica granatum) fruit extracts in a mouse mammary organ culture. Eur J Cancer Prevent. 2004;13(4):345-348.

14. Khan GN, Gorin MA, Rosenthal D, et al. Pomegranate fruit extract impairs invasion and motility in human breast cancer. Integrat Cancer Ther. 2009;8(3):242-253.

15. Adams LS, Zhang Y, Seeram NP, Heber D, Chen S. Pomegranate ellagitannin-derived compounds exhibit antiproliferative and antiaromatase activity in breast cancer cells in vitro. Cancer Prevent Res. 2010 3(1):108-113.

16. Thomas HV, Reeves GK, Key TJ. Endogenous estrogen and postmenopausal breast cancer: a quantitative review. Cancer Causes Control. 1997;8(6):922-928.

17. Malik A, Mukhtar H. Prostate cancer prevention through pomegranate fruit. Cell cycle. 2006;5(4):371-373.

18. Malik A, Afaq F, Sarfaraz S, Adhami VM, Syed DN, Mukhtar H. Pomegranate fruit juice for chemoprevention and chemotherapy of prostate cancer. Proc Natl Acad Sci U S A. 2005;102(41):14813-14818.

19. Turrini E, Ferruzzi L, Fimognari C. Potential effects of pomegranate polyphenols in cancer prevention and therapy. Oxidat Med Cell Long 2015;(2015):938475.

20. Jain KK. Nanotechnology in clinical laboratory diagnostics. Clin Chim Acta. 2005;358(1):37-54.

21. Bharali DJ, Mousa SA. Emerging nanomedicines for early cancer detection and improved treatment: current perspective and future promise. Pharmacol Ther. 2010;128(2):324-335.

22. Lee MK, Lim SJ, Kim CK. Preparation, characterization and in vitro cytotoxicity of paclitaxel-loaded sterically stabilized solid lipid nanoparticles. Biomaterials. 2007;28(12):2137-2146.

23. Bhushan S, Kakkar V, Pal HC, et al. Enhanced anticancer potential of encapsulated solid lipid nanoparticles of TPD: a novel triterpenediol from Boswellia serrata. Mol Pharm. 2013;10(1):225-235.

24. Jain AK, Jain A, Garg NK, et al. Adapalene loaded solid lipid nanoparticles gel: an effective approach for acne treatment. Colloids Surf B: Biointerfaces. 2014;121:222-229.

25. El-Say KM, El-Helw A-RM, Ahmed OA, et al. Statistical optimization of controlled release microspheres containing cetirizine hydrochloride as a model for water soluble drugs. Pharm Dev Technol. 2015; 20(6):738-746.

26. Dong Z, Xie S, Zhu L, Wang Y, Wang X, Zhou W. Preparation and in vitro, in vivo evaluations of norfloxacin-loaded solid lipid nanopartices for oral delivery. Drug Deliv. 2011;18(6):441-450.

27. Wang S, Chen T, Chen R, Hu Y, Chen M, Wang Y. Emodin loaded solid lipid nanoparticles: preparation, characterization and antitumor activity studies. Int J Pharm. 2012;430(1):238-246.

28. Montenegro L, Sinico C, Castangia I, Carbone C, Puglisi G. Idebenoneloaded solid lipid nanoparticles for drug delivery to the skin: in vitro evaluation. Int J Pharm. 2012;434:169-174.

29. Ekambaram P, Sathali AAH. Formulation and evaluation of solid lipid nanoparticles of ramipril. J Young Pharm. 2011;3(3):216-220.

30. Gil MI, Tomás-Barberán FA, Hess-Pierce B, Holcroft DM, Kader AA. Antioxidant activity of pomegranate juice and its relationship with phenolic composition and processing. J Agric Food Chem. 2000;48(10): 4581-4589.

31. Tran TH, Ramasamy T, Cho HJ, et al. Formulation and optimization of raloxifene-loaded solid lipid nanoparticles to enhance oral bioavailability. J Nanosci Nanotechnol. 2014;14(7):4820-4831.

32. Mosmann T. Rapid colorimetric assay for cellular growth and survival: application to proliferation and cytotoxicity assays. J Immunol Methods. 1983;65(1-2):55-63.

33. Gomha SM, Riyadh SM, Mahmmoud EA, Elaasser MM. Synthesis and anticancer activities of thiazoles, 1, 3-thiazines, and thiazolidine using chitosan-grafted-poly (vinylpyridine) as basic catalyst. Heterocycles. 2015;91(6):1227-1243.

34. Schwarz C, Mehnert W. Solid lipid nanoparticles (SLN) for controlled drug delivery II. Drug incorporation and physicochemical characterization. J Microencapsul. 1999;16(2):205-213.
35. Sun J, Bi C, Chan HM, Sun S, Zhang Q, Zheng Y. Curcumin-loaded solid lipid nanoparticles have prolonged in vitro antitumour activity, cellular uptake and improved in vivo bioavailability. Colloids Surf B: Biointerfaces. 2013;111:367-375.

36. Nabi-Meibodi M, Vatanara A, Najafabadi AR, et al. The effective encapsulation of a hydrophobic lipid-insoluble drug in solid lipid nanoparticles using a modified double emulsion solvent evaporation method. Colloids Surf B: Biointerfaces. 2013;112:408-414.

37. Shah B, Khunt D, Bhatt H, Misra M, Padh H. Application of quality by design approach for intranasal delivery of rivastigmine loaded solid lipid nanoparticles: effect on formulation and characterization parameters. Eur J Pharm Sci. 2015;78:54-66.

38. Hosny KM. Alendronate sodium as enteric coated solid lipid nanoparticles; preparation, optimization, and in vivo evaluation to enhance its oral bioavailability. PLoS One. 2016;11(5):e0154926.

39. Mainardes RM, Evangelista RC. PLGA nanoparticles containing praziquantel: effect of formulation variables on size distribution. Int $J$ Pharm. 2005;290(1):137-144.

40. Emami J, Mohiti H, Hamishehkar H, Varshosaz J. Formulation and optimization of solid lipid nanoparticle formulation for pulmonary delivery of budesonide using Taguchi and Box-Behnken design. Res Pharm Sci. 2015;10(1):17-33.

41. Mehnert W, Mäder K. Solid lipid nanoparticles: production, characterization and applications. Adv Drug Deliv Rev. 2001;47(2):165-196.

42. Harivardhan Reddy L, Murthy RS. Etoposide-loaded nanoparticles made from glyceride lipids: formulation, characterization, in vitro drug release, and stability evaluation. AAPS Pharm Sci Tech. 2005; 6(2):E158-E166.

43. Shah R, Eldridge D, Palombo E, Harding I. Optimisation and stability assessment of solid lipid nanoparticles using particle size and zeta potential. J Phys Sci. 2014;25(1):59-75.

44. Kovacevic A, Savic S, Vuleta G, Müller R, Keck CM. Polyhydroxy surfactants for the formulation of lipid nanoparticles (SLN and NLC): effects on size, physical stability and particle matrix structure. Int $J$ Pharm. 2011;406(1):163-172.

45. Gaur PK, Mishra S, Bajpai M, Mishra A. Enhanced oral bioavailability of efavirenz by solid lipid nanoparticles: in vitro drug release and pharmacokinetics studies. Biomed Res Int. 2014;2014:363404.

46. Tran TH, Choi JY, Ramasamy T, et al. Hyaluronic acid-coated solid lipid nanoparticles for targeted delivery of vorinostat to CD44 overexpressing cancer cells. Carbohydr Polym. 2014;114:407-415.

47. Rocha A, Wang L, Penichet M, Martins-Green M. Pomegranate juice and specific components inhibit cell and molecular processes critical for metastasis of breast cancer. Breast Cancer Res Treat. 2012;136(3): 647-658.

48. Hong MY, Seeram NP, Heber D. Pomegranate polyphenols downregulate expression of androgen-synthesizing genes in human prostate cancer cells overexpressing the androgen receptor. $J$ Nutr Biochem. 2008; 12:848-855.

49. Ming D-S, Pham S, Deb S, et al. Pomegranate extracts impact the androgen biosynthesis pathways in prostate cancer models in vitro and in vivo. J Steroid Biochem Mol Biol. 2014;143:19-28.

50. Bishayee A, Thoppil RJ, Darvesh AS, Ohanyan V, Meszaros JG, Bhatia D. Pomegranate phytoconstituents blunt the inflammatory cascade in a chemically induced rodent model of hepatocellular carcinogenesis. J Nutr Biochem. 2013;24(1):178-187.

51. Evans LM, Cowey SL, Siegal GP, Hardy RW. Stearate preferentially induces apoptosis in human breast cancer cells. Nutr Cancer. 2009; 61(5):746-753.

52. Hagen RM, Rhodes A, Ladomery MR. Conjugated linoleate reduces prostate cancer viability whereas the effects of oleate and stearate are cell line-dependent. Anticancer Res. 2013;33(10):4395-4400.

53. Tang P, Zhang L, Chan J, et al. Apoptotic effects of stearic acid, an active compound isolated from Oldenandia diffusa, on human heaptoma cells. Res J Med Sci. 2007;1:30-38. 


\section{Publish your work in this journal}

The International Journal of Nanomedicine is an international, peerreviewed journal focusing on the application of nanotechnology in diagnostics, therapeutics, and drug delivery systems throughout the biomedical field. This journal is indexed on PubMed Central, MedLine, CAS, SciSearch $\AA$, Current Contents $\AA /$ Clinical Medicine,
Journal Citation Reports/Science Edition, EMBase, Scopus and the Elsevier Bibliographic databases. The manuscript management system is completely online and includes a very quick and fair peer-review system, which is all easy to use. Visit http://www.dovepress.com/ testimonials.php to read real quotes from published authors.

Submit your manuscript here: http://www.dovepress.com/international-journal-of-nanomedicine-journal 